University of Nebraska - Lincoln

DigitalCommons@University of Nebraska - Lincoln

January 2003

\title{
Using Earth Science Research Projects to Develop Collaboration Between Scientists at a Research University and K-12 Educators: Insights for Future Efforts
}

\author{
David C. Gosselin \\ University of Nebraska - Lincoln, dgosselin2@unl.edu \\ Richard Levy \\ University of Nebraska - Lincoln, rlevy2@unl.edu \\ Ronald J. Bonnstetter \\ University of Nebraska - Lincoln, rbonnstetter1@unl.edu
}

Follow this and additional works at: https://digitalcommons.unl.edu/natrespapers

Part of the Natural Resources and Conservation Commons

Gosselin, David C.; Levy, Richard; and Bonnstetter, Ronald J., "Using Earth Science Research Projects to Develop Collaboration Between Scientists at a Research University and K-12 Educators: Insights for Future Efforts" (2003). Papers in Natural Resources. 136.

https://digitalcommons.unl.edu/natrespapers/136

This Article is brought to you for free and open access by the Natural Resources, School of at DigitalCommons@University of Nebraska - Lincoln. It has been accepted for inclusion in Papers in Natural Resources by an authorized administrator of DigitalCommons@University of Nebraska - Lincoln. 


\section{USING EARTH SCIENCE RESEARCH PROJECTS TO DEVELOP COLLABORATION BETWEEN SCIENTISTS AT A RESEARCH UNIVERSITY AND K-12 EDUCATORS: INSIGHTS FOR FUTURE EFFORTS}

David C. Gosselin

Richard H. Levy

Ronald J. Bonnstetter
Nebraska Earth Science Education Network, University of Nebraska- Lincoln, Lincoln, NE 68588-0517

ANDRILL Science Management Office, 2255 W Street, Suite 1101,University of Nebraska-Lincoln, Lincoln, NE 68588-0851

Center for Curriculum and Instruction, University of Nebraska- Lincoln, Lincoln, NE 68588-0355

\section{ABSTRACT}

The main goal of this pilot project was to improve collaboration between scientists at a large research university and K-12 educators. By involving scientists and K-12 educators in Earth systems research, we hoped to improve scientists' awareness of current pedagogy and classroom practices, improve K-12 teachers understanding of actual scientific research and expose each group to the other's unique culture. Eight research teams (comprising a scientist, pre-service teacher and an in-service teacher) participated in a four-week research experience, attended three half-day workshops, and participated in focus group interviews. This experience reinforced K-12 teachers views that scientific inquiry must be integrated into the curriculum. Several teachers indicated that the program provided a unique opportunity for collaboration and access to resources that they did not know were available. Scientists indicated that they learned more about their role and potential contributions for teaching science. However, in most cases, our program had limited success in achieving true long-term collaboration. To increase the number of successful collaborations, the following components should be included in the team-forming process: 1 . Participant profiles; 2. Project summaries; 3. Participant Statements; and 4. Pre-project participant interviews.

\section{INTRODUCTION}

Scientists, decision makers and much of the public are recognizing the need to break down many of the divisions that have separated disciplines during much of human scientific endeavor. The advent of space travel, an increase in environmental awareness, and the use of unprecedented data resources have helped scientists and the public recognize that Earth is a large system of interrelated subsystems. As a culture, we have begun to recognize that interdisciplinary initiatives are crucial to investigating and better understanding the complex system in which we live. Unfortunately, the scientific researchers who generate new knowledge and the K-12 teachers who pass it to others encounter barriers between their respective cultures. These barriers make it difficult to change our system of science education, a system that is fundamental to our nation's economic wealth, physical health and intellectual well being. A serious flaw in pre-college teacher preparation is the lack of interaction between science faculty and K-12 educators. This distance separates teaching methods from scientific content (NSF, 1996). It constitutes one of the greatest obstacles to successfully implementing the National Science Education Standards (NRC, 1996a) and their emphasis on "science as process." To create the needed changes, educators must understand what it is to "do science," and scientists must understand what it is to practice effective teaching. To better understand one another and create change, scientists and K-12 educators must collaborate (NSF, 1996; NRC, 1996b).

For collaboration to occur, all team members must feel that their skills, knowledge and experience are respected and that their contributions are valued (Figure 1b; Cook and Friend, 1993). A major barrier to collaboration is the idea that one party's skills and knowledge are more important than the others, as when scientists convey that scientific knowledge is more important to the process than the pedagogical knowledge K-12 teachers possess (Figure 1a). Scientists and K-12 teachers need to recognize that teaching and research are mutually reinforcing. They are integral parts of the effort to understand the system in which we live. Researchers acquire knowledge that is passed on through education and, in turn, education drives future research (Ireton et al., 1996). When experts in scientific research and experts in education collaborate, they recognize this relationship.

Many science faculty recognize the value of alternative pedogogical approaches (e.g., MCTP, 1998; Savarese, 1998; MacDonald and Bykerk-Kauffman, 1995). Unfortunately, they have few incentives to implement these techniques, especially within research universities (Harris 2001). This paper describes a pilot program to implement and test a strategy to foster collaboration among scientists, pre-service teachers and in-service teachers at a Carnegie Research I university. Initiated in January 2000, we combined the well-documented strategy of involving pre- and in-service K-12 teachers in research (e.g., Langford, K. and Huntley, 1999; MCTP, 1998; 2002) with workshops intended to help scientists learn about current educational strategies and National Science Education Standards. Using this approach, we expected that: 1) each group would learn about different perspectives related to inquiry-based science education; and 2) the relationships that developed during this project would establish on-going collaboration between scientists, K-12 teachers, and the teacher preparation program at the University of Nebraska-Lincoln (UNL). Following post-research experience program evaluation, we recognize that our efforts to establish collaboration had some success but were limited in key ways.

The purpose of this paper is to use post-program anecdotal and qualitative assessments, plus key 


\begin{tabular}{|l|l|}
\hline Project Titles & Earth Science Topics \\
\hline Climate change in our lifetime, facts and fallacies. & $\begin{array}{l}\text { Climate/Meteorology/Environmental } \\
\text { Change }\end{array}$ \\
\hline Analysis of soil composition with varying topography and vegetation & Grassland Ecosystems \\
\hline $\begin{array}{l}\text { Artificial windbreaks and their effect on wind speed and pressure } \\
\text { profile }\end{array}$ & Forestry/Micro-Climatology \\
\hline $\begin{array}{l}\text { Groundwater/surface water dynamics and water quality in the } \\
\text { vicinity of North Platte, Nebraska }\end{array}$ & Hydrogeology/Water Chemistry \\
\hline $\begin{array}{l}\text { Managing water movement and bromide leaching with surface } \\
\text { barriers }\end{array}$ & Soil Science/Chemistry \\
\hline Environmental interactions of the Chinchorro culture & Paleoenvironment/Anthropology \\
\hline The hyperspectral signal from moisture-stressed soybeans & Remote Sensing/Agriculture \\
\hline The use of rubidium as a corn rootworm tracer & $\begin{array}{l}\text { Environmental Toxicology/ } \\
\text { Agricultural Ecosystems. }\end{array}$ \\
\hline
\end{tabular}

Table 1. Research Project Titles.

attributes of effective collaboration (Friend and Cook, 1996), to provide insights into the development of collaborative programs that will use research experiences to improve science education.

\section{PROJECT DESIGN}

To ensure that the perspectives of all stakeholders were considered, we convened an advisory committee prior to developing the research experience. The committee consisted of the PIs, two university science faculty, two K-12 science educators, and a pre-service science educator. Based on advice from the committee, we developed the research experience described below.

Research Experience - We set up eight research teams that consisted of a scientist, a pre-service teacher and an in-service teacher. The teams conducted research at one of the UNL research and extension centers or at the main UNL campus. We asked for a minimum commitment of four weeks.

We recruited scientists through and selected them from a survey of interest given to faculty in UNL's College of Agricultural Sciences and Natural Resources, Department of Geosciences, and Conservation and Survey Division (Nebraska Geological Survey). We asked the eight scientists to develop a general description of their research project. These descriptions were circulated to educators via the internet, e-mail, and in-class visits to secondary science-methods classes at UNL. We asked in-service and pre-service teachers to apply to the program and to indicate the project they were most interested in. Project administrators used this information to create teams that best matched the interests of the research scientists and K-12 teachers. Table 1 provides the titles and Earth Science topics of the research projects.
Our initial goal was to have all team members begin the research project together. However, pre-service students and scientists were anxious to begin immediately, before K-12 teachers, who were only able to begin after the school year. Therefore, we decided that the scientists would provide the pre-service student with the necessary background knowledge and that the pre-service student would teach the in-service teacher when they joined the team in June.

To model the dissemination of scientific information, we requested from each team a scientific research paper and a curriculum unit based on the research project. We then used the research paper to evaluate the research experience and included it in the final course requirements. We did not expect that these papers should be submitted for public presentation in any form.

Summer Workshops - We required each team to attend three half-day workshops that we moderated. During the first workshop, we reviewed project goals and collected baseline data on each scientist's and in-service teacher's understanding of the nature of science using an instrument modified from Lederman (1999). We had collected data for pre-service teachers earlier in the year. The second workshop addressed the National Science Education Standards. It focused on the nature of science and its relationship to the process of inquiry-based learning. Participants created rubrics to describe how positivist, interpretive, and critical theorist paradigms (McGuire 1996) influence scientific evidence, theory, literacy, experimentation, inquiry processes, and knowledge acquisition. At the final workshop, participants shared project outcomes and insights.

Post-Project Anecdotal and Qualitative Assessment - We used the following information to generate insights into the extent to which each group learned 
What do you believe is the purpose of addressing the nature of science in your teaching?

What do you believe is the purpose of addressing scientific inquiry in the teaching setting?

In what ways would you like curriculum to be affected by our knowledge of the nature of science?

How would you like the curriculum to be affected by our knowledge of scientific inquiry?

Do you have any reservations about addressing the nature of science in your teaching?

How much of a high school curriculum do you believe should be devoted to fostering and understanding the nature of science and scientific inquiry? What percentage?

What are some examples of things that you currently do to facilitate an understanding of the nature of science and/or scientific inquiry?

Please provide your definition of the nature of science.

Please provide your definition of scientific inquiry.

How did this project impact you professionally?

\section{Table 2. Focus Group Questions}

about inquiry-based science education and the extent to which collaboration developed: 1) focus group interviews of each group at the end of the formal program involvement (interview questions are in table $2)$; 2) a modified nature of science questionnaire from Lederman (1999; Table 3); 3) daily journals; 4) research papers; 5) curriculum projects; and 6) informal conversations with project participants.

Logistics - Each scientist received $\$ 1,000$ to offset research costs. The pre-service and in-service teachers were enrolled for six graduate credits, three credits in CURR 991: Field Studies in Education - Interdisciplinary Curriculum Development, and three in NRES 896: Independent Study - Integrated Earth Science Research. Each teacher also received a $\$ 1,000$ stipend.

Results - By the end of summer 2000, the eight teams had completed a series of research projects. Seven of the eight teams produced and submitted research papers to the program PI's. Seven curriculum projects were developed.

Post-Program Perceptions - To evaluate the participants' perceptions at the completion of this program, we conducted an integrated analysis of the assessment tools outlined above in section 2.3 and identified seven themes. These are: general perspectives; thoughts regarding inquiry, ideas regarding curriculum, nature of science (NOS), assessment and accountability, thoughts regarding communication, and perceptions regarding information/knowledge flow. A summary of attitudes, perceptions and observations that comprise each of the themes follows.

\section{General perspectives}

\section{In-service teachers}

Saw that scientific research is less well-defined than expected.

-Discovered that the scientific method is not as clear-cut as expected.

.Found out that the "real" process of science was not understood prior to the research experience.

\section{Scientists}

-Realized that teachers can "do science."

-Developed an understanding of what teachers experience in schools.

-Gained a greater appreciation for what classroom teachers do.

\section{Inquiry}

\section{In-service teachers}

-Inquiry is both fun and a natural learning process.

-To have true inquiry, students must develop a sense of ownership - "We need to personalize learning..."

.Science must be engaging on a personal level "Instead, we typically alienate."

By its nature, science IS inquiry.

Pre-service teachers

-Are very concerned about not having sufficient content knowledge.

Question how to find time to do inquiry and still "cover" the content.

-Recognize that inquiry is a better way to get at content

\section{Scientists}

-Believe that inquiry is the application of the nature of science.

-Recognize that K-12 teachers should be teaching through inquiry.

-Do not recognize that they should also teach through inquiry.

\section{Curriculum and Pedagogy}

\section{In-service teachers}

-Using the inquiry process is important - "It gives meaning to facts (content)."

.Students need to feel they "own" the process and the content.

-Students need a flexible curriculum that allows student-driven inquiry.

-Curriculum must be holistic, integrated, and dynamic. -Learning needs to be student-centered.

Pre-service teachers

."The inquiry process is important." - It gives meaning to the content.

. "I'll be the only one trying to teach this way" (students, colleagues, and administrators will oppose it and me).

-We need to use constructivist approaches on a day-to-day basis, this will take a lot of time.

.We need to teach people to think, not just to know.

\section{Scientists}

."The process is important." - It gives meaning to the content. 

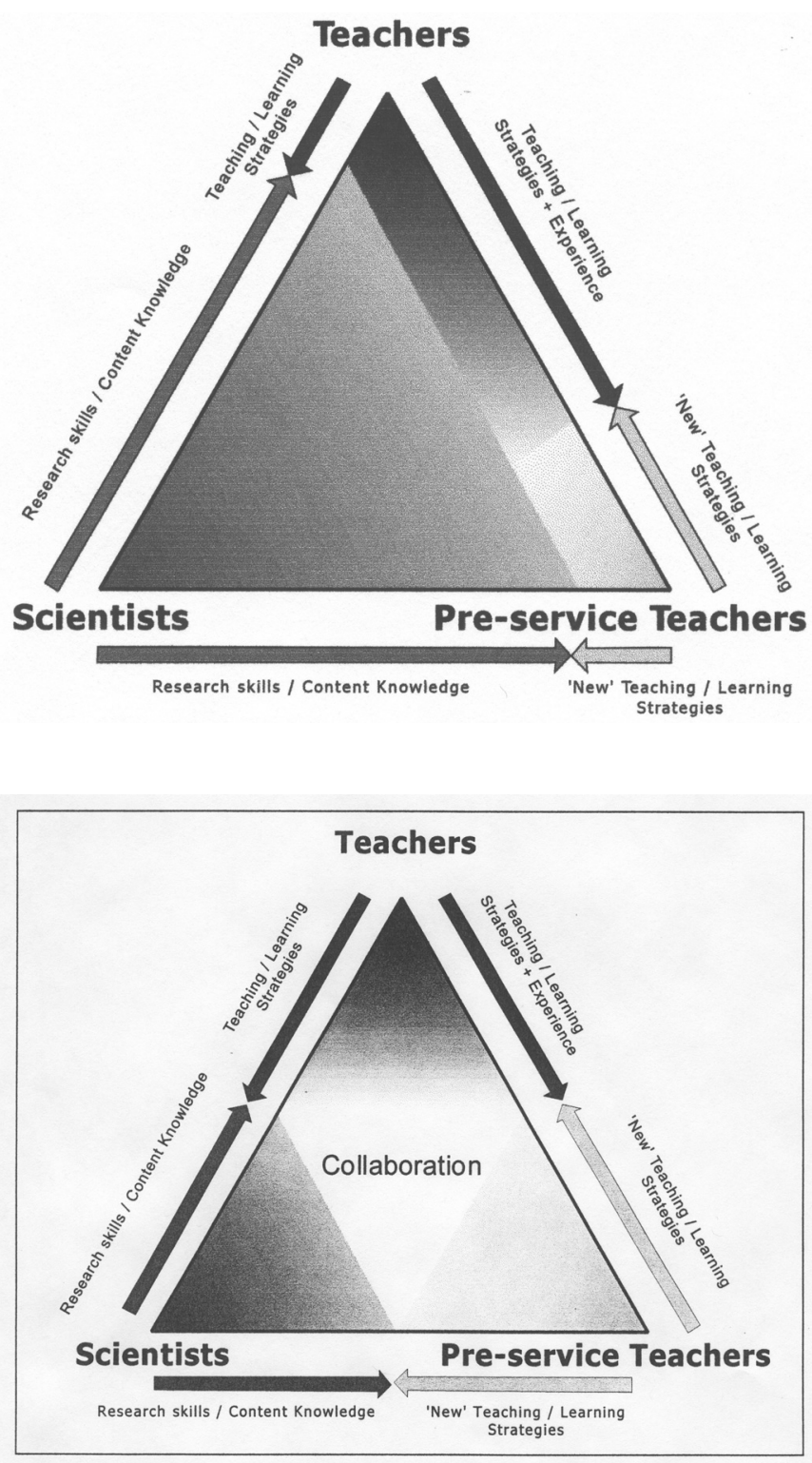

Figure 1a. (Top) One perspective of the current relationship between classroom teachers, pre-service teachers, and scientists at large research institutions: the research skills and content knowledge of the scientists are more important to changing science education than the teaching and learning strategies the educational groups offer. This perspective is based on anecdotal evidence and personal experiences. Figure 1b (Bottom) Collaboration requires that the skills, knowledge and experience of all involved are recognized and that all perspectives are valued.
-K-12 curriculum is often out of date (textbooks are not dynamic). - "Need a dynamic \& current curriculum." Information is always changing.

-Most scientists could not, or would not, address their curriculum. They automatically addressed K-12 curriculum.

-Many failed to recognize that they have a responsibility to evaluate and modify their teaching practices.

Nature of Science (NOS) - All groups have a limited understanding of the distinction between inquiry and the NOS, i.e. none of the groups recognized that the inquiry process is a part of the NOS. Many indicated that inquiry is the NOS.

Assessment and Accountability - We identified the following ideas for all groups: Facts are easier to teach and easier to assess. Teaching facts is safer and risks less controversy.

Connections and Community - This project established connections that did not previously exist - within groups as well as between them:

The contacts I made through the program have been invaluable. One researcher contacted me looking for someone to work in the lab; the job information was circulated here at Lincoln High School and a very capable young man was selected. My contact with The Nature Conservancy will provide real opportunities for students to do real field work that The Nature Conservancy will use for real decisions.

Knowledge Flow - In most cases (80\% of the teams), scientists were perceived, by both themselves and the teachers, as providing expertise and knowledge, i.e. scientists are givers and teachers are receivers (Figure 1a). The remaining teams $(20 \%)$ established a more collaborative relationship whereby all parties contributed expertise and knowledge (Figure 1b).

On-Going Collaboration - To determine the extent of on-going communication that resulted from participation in this program, in October 2002, we contacted four of the scientists who had participated in the program and asked them the following questions: Have you collaborated (or at minimum been in contact with) any of your research team since the NESEN program ended? If so, what have you done?

Two of the scientists have been in contact with their team members. Each scientist had visited the teacher's school to teach classes. One of the scientists had communicated with the team's teacher to answer specific science questions. The other scientist had worked with the teacher to develop curricula for high school students. Furthermore, these two individuals collaborated on a research proposal and are currently discussing a proposal to develop an educational program targeting American Indians. The other two scientists have had no contact with their team members.

\section{DISCUSSION}

Insights Related to Inquiry at the K-12 Level - One of the ultimate goals of science education reform is to 
increase open-ended scientific inquiry in the classroom. Open-ended inquiry promotes free thought and creative approaches to problem solving, valuable skills that can be used in many aspects of life. If we expect educators to effectively teach science process skills and scientific inquiry, they need to have some level of first-hand experience with these processes (e.g., MCTP, 1998, 2002; Langford and Huntley, 1999). One teacher commented,

The project gave me insight into how to teach scientific inquiry in the classroom. I feel I am better prepared to teach the content. My approach will be student-centered, where they make decisions on how to address various issues, and I am simply the facilitator.

At the outset of their research projects, many teachers expected that their projects would have a definitive beginning and end. Upon completing the research experience, they recognized that scientific inquiry is often a journey without a specified final destination as reflected in the following comment. "'We would try one method, see it fall apart, and then scramble to come up with another method."

One of the fundamental and challenging parts of scientific inquiry is developing a research question or defining a specific problem. Because most of the teachers joined an established research project, they did not get to develop the research question on which they would work. If we expect K-12 teachers to establish open-ended inquiry in their classroom, then our research programs must provide K-12 teachers the opportunity to develop their own research plan. They must be able to modify their plan as the project proceeds. They must be allowed to discover that the problem may not have a final answer.

$\mathrm{K}-12$ teachers gained experience in scientific inquiry during this program. However, experience in inquiry alone does not automatically translate into inquiry-based curriculum. The curriculum projects that the K-12 teachers developed at the end of their research experience clearly reflected this fact. Some curriculum projects were more open-ended and inquiry-oriented than others. K-12 teachers recognized the effectiveness of inquiry but most were unable to implement inquiry within a pedagogical framework. Future programs need to create ways to provide additional opportunities to explore educational applications of the inquiry process so that participants can effectively transfer the experience to their classrooms. Many K-12 teachers need to be convinced that an inquiry-based curriculum can satisfy content responsibilities. Future programs should clearly model how this can be achieved.

Insights into Influencing Pedagogical Practice of Scientists at a Large Research University - One of the unique aspects of this project was that research scientists were encouraged to think about how science should be taught. Through interaction with K-12 teachers and participation in program workshops, the scientists became more aware of the challenges $\mathrm{K}-12$ educators face. They also identified inadequacies in the local K-12 system, especially in keeping curriculum materials current. However, most failed to recognize the role that they must play in meeting the goals of standards-based reform. Most scientists did not acknowledge that they need to employ inquiry in their own teaching. Furthermore, during discussions related to curriculum, scientists generally ignored their own curriculum and jumped immediately to K-12 curriculum. Although many factors may have contributed to this jump, we suggest that most of the scientists did not see themselves as having to evaluate their own pedagogical approaches. In this respect, our project design fell short of its goals. However, we are encouraged that two of the scientists indicated that they have a responsibility to learn better teaching practices. The following quotes are taken from a post-project questionnaire that was given to scientists:

I think anyone interested in education should constantly assess the opportunities to be a better educator and be as connected to the educational process as possible. Anything we can do to stay more connected to our subject matter and the people we try to share it with has my support.

The program formalized my thinking and approach to teaching. I think that I had always been a discovery-based teacher but never knew there was a term or method for what I did. I also never knew that there was a community of like-minded teachers. Having learned this, I applied this approach in my Fulbright Commission funded teaching stay in Brazil. There I found that discovery based teaching is great for effectively crossing cultural/linguistic boundaries.

Locally, I and my LPS colleague have continued to work together.

The challenge remains to get more scientists at large research universities to clearly recognize their pedagogical role in meeting the goals of standards-based reform.

Insights Related to Building Collaborative Teams Several of the teams formed a working relationship very quickly and as a result, identified tasks to be accomplished, divided responsibilities and worked like a fine-tuned machine. Why were some of our research teams far more productive than others? Why did these teams accomplish much more than the others and what can we do in the future to build more effective research teams?

One key may lie in taking more time to form the teams. As is the case in most research teams, the driving force for establishing team make-up was the research to be accomplished. The only connection requested was that team members be willing to work together on a question established by the scientist. We were asking these people to work together on tasks that in many cases had never been done before and assumed that a working relationship would form around that tie to a common interest. As we examined the effectiveness of the teams, as defined by both products created and comments from interviews about their working relationships, we found that those more productive teams had formed working relationships that became a driving force to their work. They possessed collaborative qualities that were lacking from less effective groupings. So while we were creating working teams, with a focus on the "what" these teams would do, we invested no time or energy in "how" individuals were to work together.

Cook and Friend (1993) define collaboration as a working relationship that professionals choose to use in order to accomplish a goal they share. The question that emerges is: What are the characteristics of these highly 
effective teams, and what can we do to increase the probability that teams will function in this manner?

Characteristics of Collaboration - Friend and Cook (1996) provide the following key attributes of effective collaboration. Figure $1 \mathrm{~b}$ graphically summarizes these characteristics in the context of the parties involved in this project.

Collaboration is voluntary. While all in this project volunteered to participate, the nature of this collaboration becomes extremely important as we try to institutionalize the concept. If true collaborations are to develop within our teams, intrinsic motivation must be used whenever possible. Team members must see value in the partnership and feel that they had a clear choice to participate. Faculty can be recruited but not coerced. Pre-service teachers can be required to have inquiry experiences, but the details and commitment must be left to them; and classroom teachers must freely choose to be involved. You cannot force people to collaborate.

Collaboration is based on parity. Each member of a collaborative team must see that their contributions are equally valued, even if those contributions are drastically different. In this project, highly effective teams had members who developed and contributed unique skills for the good of the entire project, and all members valued the contributions made by each member. For example, the scientist was certainly the topic expert, but the classroom teacher knew how research findings ultimately had to be packaged to create curriculum and the pre-service teacher many times became the skilled technician who held the key to good test results.

Collaboration requires a shared goal. The most effective teams shared a common vision of the task and the desired outcomes. They spent far more time together than other project groups and, as a result, communicated with each other far more often. This time on task and open communication also facilitated the next key attribute.

Collaboration includes shared responsibility for key decisions. The most effective teams jointly discussed key decisions of research design and interpretation and every member made contributions. On the other end of the spectrum, in the least effective teams, generally a scientist told members what to do and when. As a result, team members did not fully understand the goal, nor were they invested in the outcomes. They were not treated as equals and acted accordingly.

Collaboration includes shared accountability for outcomes. Because members of effective teams -favored direct input into key decisions, they stood ready to take full responsibility for accomplishing the needed tasks. In addition, because they established open communication, members knew their roles and felt a sense of responsibility to each other.

Collaboration is based on shared resources. Just as each member must have a sense of parity, members must feel that their contribution plays a crucial role in task accomplishment. Team members can contribute time, space, equipment, expertise or other assets.
Collaboration is emergent. While many of these key attributes are important from the outset of project activities, the best collaborations grew as the relationships among team members grew. For example, the most effective team still meets once a week to discuss their efforts, two years after the project ended. They have seen the results when mutual respect and trust in each member's expertise can develop. This last attribute clearly suggests that short-term projects, designed for a few hours or even a couple of weeks, may fail to provide the time needed to develop effective collaboration. Only on the team where all members felt that their contributions were valued, that the goal was clear, and where they shared decision-making and respected each contribution did true collaboration exist.

\section{CONCLUSIONS}

This research program was designed to provide a framework for collaboration between scientists at a research university and K-12 educators. We involved scientists and teachers in team research projects and provided them with opportunities to reflect on the national and local educational system. Our project helped scientists and teachers learn more about the other's expectations and perceptions. Simply put, each group has a better understanding of the other's culture. The recognition and respect of "cultural" differences is critical to the development of collaboration. This respect is vital to implementing standards-based reform and its emphasis on "science as process." Although we had limited success in establishing on-going collaboration, we believe that future programs should apply the following approach to developing collaborative teams.

Develop Participant Profiles - Use personality instruments to develop a profile of each participant's learning styles, personality traits, and communication styles. These profiles will help organizers build collaborative teams.

An effective team must have members that understand each others values and expectations. These personal qualities can be identified by asking individuals to complete behavior and value inventories prior to forming teams (e.g. Bonnstetter et al. 1993). The goal is not to fashion teams around particular styles, but to provide insights into each member's working behavior and underlying values. These insights will allow better communication because expectations will be known at the outset, rather than discovered later during stressful or negative interactions.

Personal dispositions are guided by beliefs and attitudes. For example, one member might believe that the end product is the most important outcome, while another may believe that the process is the primary focus. In another case, one member might be detail-oriented while another may focus on the big picture. Dealing with such different perspectives became a major challenge for several teams in our program. This challenge could have been minimized if we understood individual dispositions before creating teams.

Project Summaries - Scientists must provide a project description that clearly defines the role that $\mathrm{K}-12$ participants will have in the project. However, K-12 teachers need to help define and modify the project's goals and approaches. 
Participant Statements - Scientists need to specify the minimum level of scientific knowledge and skills they require. Alternatively, scientists must indicate that they are willing to teach participants who might lack some of the required skills. In-service and pre-service teachers need to provide a resume, a list of skills, and a statement of scientific interests. Scientists need to commit to direct involvement with other team members. Program organizers need to recruit scientists who are willing to commit time up-front. During this project, several scientists indicated that they would be directly involved but then took a hands-off approach. Some didn't show for the workshops. Active participation must be required of all participants.

Pre-project Interview - Before a team is established, potential members must meet and develop a clear image of the expectations of all. Once the teams are formed and research begins, program organizers need to monitor each to assess the level of collaboration and to provide mechanisms for team members to reflect on their experiences from both a pedagogical and scientific perspective. Without such reflection, it will be difficult for participants to identify and resolve problems and to determine what they have learned from the experience.

\section{ACKNOWLEDGEMENTS}

Funding from the Geosciences Directorate of the National Science Foundation, Grant No. EAR-9907759. We would also like to acknowledge the participation of the scientists, teachers and students for their enthusiastic participation. Reviews by Drs. G. R. Whittecar and P. Harnik plus an anonymous reviewer helped us focus the paper significantly. Editorial review by C. Flowerday is also gratefully acknowledged.

\section{REFERENCES}

Bonnstetter, W., Suiter, J.I., and Widrick, J.I., 1993, The Universal Language DISC, A Reference Manual. Scottsdale, AZ, Target Training International.

Bower, J. M., 1996, Science education reform: How can we help?, Issues in Science and Technology, p. 55-60.

Cook, L., and Friend, M., 1993, Educational leadership for teacher collaboration, in, B. Billingsley (Ed.), Program leadership for serving students with disabilities, Virginia Department of Education, Richmond,VA, p. 421-444.

Friend, M., and Cook, L., 1996, Interactions: Collaboration skills for school professionals (2nd ed.), Longman, White Plains NY.

Harris, M.T., 2001, Strategies for implementing pedagogical changes by faculty at a research university, Journal of Geoscience Education, v. 49, 50-55.
Ireton, M.F.W., Manduca, C.A., and Mogk, D.W., 1996, Shaping the future of undergraduate earth science education: Innovation and change using as Earth System Approach, Report of a workshop convened by the American Geophysical Union in cooperation with the Keck Geology Consortium and with support from the National Science Foundation. 61p.

Langford, K., and Huntley, M.A., 1999, Internships as Commencement: Mathematics and science research experiences as catalysts for preservice teacher professional development Journal of Mathematics and Teacher Education, v. 2, 277- 299.

Lederman, N. G., 1999, Teachers' Understanding of the Nature of Science and Classroom Practice: Factors That Facilitate or Impede the Relationships, Journal of Research in Science Teaching. v. 36, p. 916-929.

Macdonald, R. H., and Bykerk-Kauffman, A., 1995. Collaborative and cooperative activities as tools for teaching and learning geology, Journal of Geological Education, v. 43, p. 305.

Maryland Collaborative for Teacher Preparation (MCTP), 1998, Journeys of Transformation: A statewide effort by mathematics and science professors to improve student understanding, Gardner, M.B. and Ayers, D.L., (eds). Towson State University, 166p.

Maryland Collaborative for Teacher Preparation (MCTP), 1998, Journeys of Transformation II: The impact of the Maryland Collaborative for Teacher Preparation on Science and Mathematics Instruction, Bell, C. and Dennsiton, C.J., (eds). Towson State University, 175p.

McGuire, P., 1996, World Wide Web:http://www. pmcguire.demon.co.uk. Scientifparadigmsgamutgram.html. Acquired 11/04/02.

National Research Council, 1996, Center for Science, Mathematics and Engineering Education. From Analysis to Action: Undergraduate education in science, mathematics, engineering, and technology, A report of a convocation. National Academy Press, Washington D.C.

National Science Foundation (NSF) 96-139, 1996, Shaping the Future: New expectations for undergraduate education in science, mathematics, engineering, and technology. A report on its review of undergraduate education by the Advisory Committee to the National Science Foundation Directorate for Education and Human Resources.

Savarese, M., 1998, Collaborative learning in an upper-division university geobiology class, Journal of Geoscience Education, v. 46, p. 61-66. 